\title{
PENERAPAN STRATEGI BELAJAR SQ4R UNTUK MENINGKATKAN HASIL BELAJAR PESERTA DIDIK PADA POKOK BAHASAN STRUKTUR ATOM DI KELAS X MIA SMA MUHAMMADIYAH 1 PEKANBARU
}

\author{
Rinchian Fristi *, Roza Linda, Johni Azmi
}

Program Studi Pendidikan Kimia, Fakultas Keguruan dan Ilmu Pendidikan Universitas Riau, Kampus Binawidya KM 12,5, Pekanbaru 28293, Riau, Indonesia.

\begin{tabular}{l}
\hline \multicolumn{1}{c}{ Informasi Artikel } \\
\hline Sejarah Artikel: \\
Diterima: 19-07-2019 \\
Disetujui : 29-01-2020 \\
Dipublikasikan: 30-01-2020 \\
\hline Keywords: \\
Learning process \\
Experimental inquiry, \\
SQ4R, \\
Learning Enhancement, \\
Atomic Structures. \\
\\
\hline
\end{tabular}

\begin{abstract}
A b s t r a k
Penelitian penerapan strategi belajar SQ4R (Survey, Question, Read, Recite, and Review) untuk meningkatkan hasil belajar peserta didik pada materi struktur atom pada kelas X MIA Muhammadiyah 1 Pekanbaru telah dilaksanakan dari bulan Agustus sampai September tahun 2018. Penelitian eksperimen dengan desain pre-test dan post-test digunakan dalam penelitian. Ada dua sampel yang digunakan yaitu kelas X MIA 2 sebagai kelas eksperimen dan kelas X MIA 3 sebagai kelas kontrol. Kedua kelas dipilih secara acak setelah sebelumnya dijalankan uji normalitas dan uji homogenitas. Kelas eksperimen mengimplementasikan strategi belajar $S Q 4 R$. T-test digunakan sebagai teknik analisa data. Dari data akhir yang diproses dengan t-test didapatkan $\mathrm{t}$ hitung $>\mathrm{t}$ table $(1,86>1,67)$. Ini menunjukkan bahwa strategi belajar $S Q 4 R$ dapat meningkatkan hasil belajar peserta didik kelas X MIA SMA Muhammadiyah 1 Pekanbaru pada materi struktur atom.
\end{abstract}

\begin{abstract}
A b s tract
The study of the Survey, Question, Read, Recite, and Review (SQ4R) employment to enhance students' learning achievement on atomic structures in X MIA SMA Muhammadiyah 1 Pekanbaru has been conducted from August until September 2018. Experimental inquiry with pre-test and post-test design was used in the study. Two samples used in the study were X MIA 2 for the experimental class and X MIA 3 for the control class. Both classes were randomly selected after normality and homogeneity test had been run upon them. The experimental class has implemented the SQ4R learning strategy. A t-test is applied as the data analyze technique. The final data of the study processed by using t-test formula has shown the obtained score as $t$ count > t table $(1,86>1,67)$. This shows that SQ4R implementation could enhance students' achievement on atomic structures subject in X MIA SMA Muhammadiyah 1 Pekanbaru.
\end{abstract}

(C) 2020 Universitas Riau

\footnotetext{
*Alamat korespondensi:

E-mail: rinchian.fristi@yahoo.co.id

No. Telf: 085265359841
} 


\section{PENDAHULUAN}

Kualitas pendidikan dapat ditingkatkan jika tujuan pembelajaran di dalam proses belajar dan mengajar dapat dicapai. Demi tercapainya hal tersebut, guru sebagai pendidik dan peserta didik sebagai subjek yang aktif dalam belajar harus memiliki kesadaran akan pentingnya belajar. Peserta didik yang aktif berpartisipasi dalam proses pembelajaran dapat menciptakan pembelajaran yang lebih efektif (Dimyati dan Mudjiono, 2002). Aktifnya peserta didik menambah pengalaman tersendiri bagi dirinya yang pada akhirnya mempengaruhi keoptimalan hasil belajar.

Ilmu kimia sebagai salah satu cabang ilmu pengetahuan alam merupakan ilmu yang mempelajari komposisi dan sifat zat dari skala atom hingga molekul. Ilmu kimia juga menganalisa perubahan serta interaksi suatu zat untuk membentuk materi di alam. Nobuga (2008) mengatakan, sebagai bagian dari sains, ilmu kimia berkaitan dengan bagaimana cara mencaritahu dan memahi alam secara sistematis. Keterampilan, proses berpikir untuk memahami, menemukan, mengembangkan konsep, teori dan hukum serta pemecahan masalah dalam kehidupan sehari-hari diperlukan oleh siapapun yang mempelajari ilmu kimia. Ini dikarenakan pokok bahasan dalam ilmu kimia tidak hanya tentang menghapal, tetapi dibutuhkan juga pemahaman, analisa, dan kemampuan peserta didik dalam mengaitkan pembelajaran ke kehidupan sehari-hari, khususnya dalam materi struktur atom.

Infromasi yang diperoleh dalam hasil wawancara dengan guru kimia di SMA Muhammadiyah 1 Pekanbaru bahwa guru masih menggunakan metode ceramah, tanya jawab dan diskusi terbimbing dalam proses belajar mengajar. Hal ini dikarenakan ketiga metode itu lebih mudah dan efisien dalam waktu saat digunakan. Dari segi peserta didik, ilmu kimia masih dianggap mata pelajaran yang sulit. Kurangnya kompetensi guru dalam penggunaan metode dan model pembelajaran dan ilmu kimia yang bersifat abstrak menjadi faktor-faktor yang membuat ilmu kimia masih sulit dipahami oleh peserta didik (Ashadi, 2009). Ini membuat minat peserta didik akan ilmu kimia kurang dan bahkan ada yang tidak menyukainya. Karena sulit dan kurangnya minat peserta didik dalam ilmu kimia, mereka mengalami kendala dan tidak mandiri dalam mempelajarinya. Sikap kurang aktifnya peserta didik, jarang bertanya saat proses belajar dan mengajar di kelas, dan sikap pasif peserta didik saat mendengar ceramah guru, merupakan bukti-bukti kurangnya minat belajar ilmu kimia.

Strategi belajar yang digunakan memiliki pengaruh yang signifikan dalam menanamkan konsep dan keterampilan ilmu kimia pada peserta didik. Strategi belajar ini haruslah strategi yang membuat peserta didik mudah memahami konsep-konsep kimia. Penggunaan strategi belajar SQ4R (Survey, Question, Read, Recite, Record, and Review), atau menyelidik, menanyakan, membaca, menceritakan, mencatat, dan mengulas, diimplementasikan agar peserta didik dapat memahami konsep-konsep kimia dengan mudah demi tercapainya tujuan pembelajaran. Membantu peserta didik tentang apa yang mereka baca melalui kegiatan aktif merupakan garis besar pelaksanaan strategi belajar SQ4R ini. Peserta didik dibagi dalam beberapa kelompok. Di setiap kelompok peserta didik membaca buku paket mereka, setelah itu mereka aktif mencari serta memahami materi dari teks atau buku melalu tahapan-tahapan starategi SQ4R. Dengan demikian, peserta didik lebih mudah untuk mengingat materi. Beberapa publikasi yang telah melaporkan pembelajaran berbasis SQ4R untuk meningkat prestasi belajar peserta didik. Usman et al (2019) telah mengembangkan SQ4R untuk meningkatkan hasil belajar peserta didik pada materi hidrokarbon. Penelitian ini diharapkan mencapai hasil yang diinginkan karena telah dilaksanakan penelitian sejenis oleh Aris Gunawan (2016) dengan judul penelitian Penerapan Strategi SQ4R Untuk Meningkatkan Aktivitas dan Hasil Belajar Larutan Penyangga Bagi Peserta Didik Kelas XI IPA-1 SMAN 1 Cepiring. Dari penelitian tersebut diperoleh hasil terdapatnya peningkatan aktivitas belajar sebesar 66,29\% dan hasil belajar sebesar 38, $27 \%$.

Dalam kajian ini difokuskan pada penerapan pembelajaran SQ4R untuk meningkatkan hasil belajar peserta didik di Sekolah Menengah Atas. Model pembelajaran SQ4R ini diimplementasikan pada Sekolah Menengah Atas Muhamadiyah 1 Pekanbaru pada pokok 
bahasan Struktur atom di kelas $\mathrm{x}$.

\section{METODE PENELITIAN}

Penelitian dilakukan di SMA Muhammadiyah 1 Pekanbaru. Waktu penelitian yaitu pada semester ganjil tahun ajaran 2018/2019. Populasi penelitian adalah kelas X MIA yang terdiri dari dua kelas. Sampel penelitian diambil secara acak berdasarkan nilai pre-test uji normalitas dan homogenitas. Dari hasil pre-test, dipilih kelas X MIA 2 sebagai kelas eksperimen dan kelas X MIA 3 sebagai kelas kontrol. Penelitian eksperimen digunakan sebagai bentuk penelitian. Dilakukan terhadap dua kelas dengan desain pre-test dan post-test seperti Tabel 1.

Tabel 1. Rancangan Penelitian (Nazir, 2003)

\begin{tabular}{cccc}
\hline Kelas & Pre test & Perlakuan & Post Test \\
\hline Eksperimen & T0 & $\mathrm{X}$ & T1 \\
Kontrol & T0 & - & T1 \\
\hline
\end{tabular}

\footnotetext{
Keterangan:

$\mathrm{X}$

$=$ Perlakuan terhadap kelas eksperimen dengan menggunakan strategipembelajaran SQ4R

T0 = Hasil pre-test kelas eksperimen dan kelas kontrol

$\mathrm{T} 1 \quad=$ Hasil post-test kelas eksperimen dan kelas kontrol

Pre-test $\quad=$ tes awal sebelum pembelajaran struktur atom

Post-test $\quad=$ tes akhir setelah pembelajaran struktur atom
}

Teknik pengumpulan data yang digunakan dalam penelitian ini adalah teknik test. Penjelasan rinciannya adalah sebagai berikut. Data yang dikumpulkan diperoleh dari: (1) Hasil tes materi prasyarat; (2) Pre-test, yaitu pelaksaan tes pada kedua sampel kelas sebelum memasuki materi struktur atom; (3) Post-test, yaitu pelaksanaan tes pada kedua sampel kelas setelah proses belajar mengajar materi struktur atom selesai dilaksanakan.

Untuk teknik analisa data adalah dengan menggunakan uji-t untuk penelitian ini. Uji statistik dengan uji-t dapat dilakukan berdasarkan kriteria data yang terdistribusi normal. Sebelum dilakukan pengolahan data baik data hasil pre-test maupun post-test pada penelitian ini, dilakukan terlebih dahuli uji normalitas menggunakan uji Liliefors. Jika harga Lmaks $<$ Ltabel, maka data terdistribusi normal. Harga Ltabel diperoleh dengan rumusan (1) (Irianto, 2003) :

$$
L=\frac{0,886}{\sqrt{n}}
$$

Jika data telah terdistribusi normal, selanjutnya menguji varians kedua sampel sebagai bentuk uji homogenitas (homogeny atau tidaknya sampel), dengan rumus (2):

$$
\mathrm{F}=\frac{\text { Varians Terbesar }}{\text { Varians Terkecil }}
$$

Kemudian dilakukan uji kesamaan rata-rata menggunakan uji-t dua pihak untuk mengetahui kehomogenan kemampuan kedua sampel. Rumus uji-t pada uji homogenitas juga digunakan untuk melihat perubahan hasil belajar peserta didik pada kelas eksperimen dan kelas control. Rumusan uji-t 
sperti pada persamaan (3)

$$
\mathrm{t}=\frac{\bar{x}_{1}-\bar{x}_{2}}{S_{g \sqrt{\frac{1}{n_{1}}+\frac{1}{n_{L}}}}}
$$

dengan $\mathrm{Sg}$ merupakan standar deviasi gabungan yang dapat dihitung dengan menggunakan persamaan (4):

$$
S_{g}^{2}=\frac{\left(n_{1}-1\right) S_{1}^{2}+\left(n_{L}-1\right) S_{L}^{2}}{n_{1}+n_{2}-2}
$$

\section{HASIL DAN PEMBAHASAN}

Selisih antara nilai post-test dan pre-test digunakan sebagai data untuk uji hipotesis. Hasil analisis uji hipotesis terdapat pada Tabel 2.

Tabel 2. Hasil uji hipotesis

\begin{tabular}{lcccccccc}
\hline \multicolumn{1}{c}{ Kelas } & $\mathbf{N}$ & $\boldsymbol{\Sigma} \boldsymbol{X}$ & $\boldsymbol{\Sigma} \boldsymbol{X}_{\mathbf{2}}$ & $\begin{array}{c}\text { Xrata- } \\
\text { rata }\end{array}$ & Sgab & t tabel & t hitung & Ket. \\
\hline Eksperimen & 32 & 2105 & 139487,5 & 65,78 & 7,53 & 1,76 & 1,86 & Hipotesis \\
Kontrol & 27 & 1677,5 & 106381,3 & 62,13 & & & & diterima \\
\hline
\end{tabular}

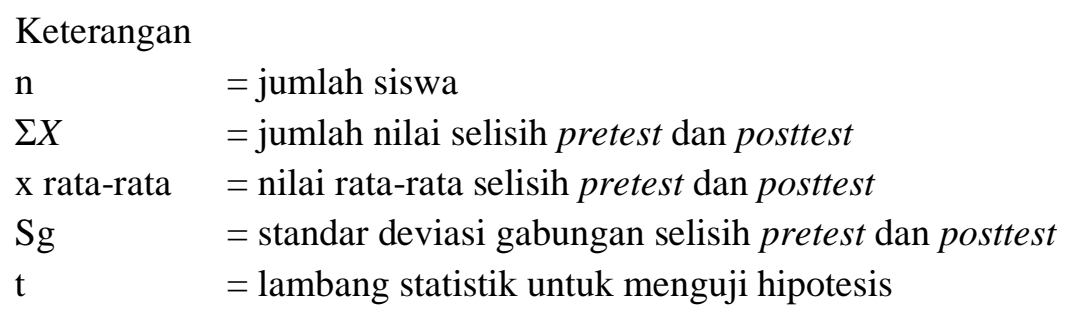

Uji hipotesis penelitian ini menggunakan uji-t pihak kanan. Hipotesis diterima jika $t$ hitung $>t$ tabel dengan $\mathrm{dk}=\mathrm{n} 1+\mathrm{n} 2-2$, kriteria probabilitas $1-\alpha$ dengan $\alpha=0,05$. Berdasarkan Tabel 2, nilai thitung $=1,86$ dan ttabel $=1,67$ sehingga diperoleh thitung $>$ ttabel, yaitu 1,86>1,67. Berdasarkan perolehan nilai thitung>ttabel, yaitu 1,86 >1,67, maka hipotesis "penerapan strategi belajar Survey, Question, Read, Recite, Record, and Review (SQ4R) dapat meningkatkan hasil belajar peserta didik pada materi struktur atom kelas X MIA SMA Muhammadiyah 1 Pekanbaru" diterima. Hasil ini mengindikasikan bahwa penerapan strategi belajar SQ4R pada proses belajar materi struktur atom dapat meningkatkan hasil belajar peserta didik dibanding dengan yang tidak menggunakan strategi belajar SQ4R.

Keterlibatan dan aktifnya peran peserta didik yang menjadi inti strategi pembelajaran SQ4R meningkatkan hasil belajar peserta didik pada materi struktur atom. Strategi ini, sesuai namanya, memiliki tahap-tahap yang harus dilalui setiap peserta didik. Proses pembelajaran dimulai dengan tahap survey atau penelitian pendahuluan. Peserta didik yang telah dibagi dalam beberapa kelompok diberi teks bacaan mengenai struktur atom. Pada tahap survey, mereka meninjau bacaan tersebut sehingga diperoleh gambaran mengenai materi yang akan dipelajari. Tahap ini menimbulkan 
keinginan peserta didik untuk lebih mengetahui materi lebih dalam, atau dengan kata lain munculnya motivasi. Haryadi (2007) mengatakan bahwa semakin banyak peserta didik membaca, maka semakin banyak mereka memperoleh pengetahuan.

Question, menjadi tahapan yang kedua. Pada tahap ini peserta didik membuat pertanyaan tentang bacaan yang baru mereka baca. Petunjuk atau contoh dalam menyusun pertanyaan diberikan oleh guru kepada peserta didik. Tujuan dari pembuatan pertanyaan ini adalah: 1) mengarahkan pesertad didik menemukan isi bacaan, 2) memotivasi peserta didik dalam untuk membaca dengan sungguh- sungguh, 3) dengan pertanyaan yang dibuat, peserta didik akan membaca dengan hati-hati dan membantu mengingat isi materi (Haryadi, 2007)

Tahap ketiga, yaitu read. Peserta didik membaca teks kembali dan mencari jawaban atas pertanyaan yang mereka buat di tahap kedua. Tahap ini merupakan tahapan yang krusial karena peserta didik dapat mencari jawaban atas pertanyaan mereka sendiri di dalam teks bacaan secara seksama (Aris Sohimin, 2014). Selain menjawab pertanyaan sendiri, peserta didik juga menjawab pertanyaan yang tersedia di LKPD untuk lebih menguatkan konsep akan materi struktur atom mereka.

Pembelajaran dilanjutkan dengan tahap keempat, yaitu recite. Mempertimbangkan jawaban yang telah didapat adalah hal yang harus peserta didik lakukan pada tahap ini. Atau dengan kata lain, membacakan jawaban yang telah mereka peroleh tanpa melihat catatan. Jika mereka mengalami kesulitan, mereka harus menjwab pertanyaan selanjutnya sampai bisa dengan baik.

Record, yang menjadi tahap kelima mewajibkan peserta didik menandai atau mencatat perihal atau bagian-bagian yang telah dipahami atau dicapai dari empat tahap sebelumnya. Tidak hanya itu, jika terdapat hal baru yang terlewat dari empat tahap sebelumnya, atau ada pengetahuan baru berhubungan dengan materi, peserta didik dapat menambahkan catatan kecil pada tahap ini. Keuntungannya, mereka bisa memahami materi secara keseluruhan tanpa harus membaca bukunya lagi.

Strategi pembelajaran SQ4R ditutup dengan tahapan review atau meninjau ulang. Peserta didik mengulas kembali semua materi secara kesluruhan dengan cara membandingkan jawaban mereka dengan buku paket, atau bertukar informasi dengan kelompok lainnya melalui presentasi kelas. Hasil pengambilan data berupa penilaian LKPD, evaluasi serta post-test menunjukkan bahwa kelas eksperimen mendapat hasil yang lebih tinggi daripada kelas kontrol. Keaktifan peserta didik dalam menjalankan strategi SQ4R memberi andil yang cukup dalam hasil tersebut. Ini dapat dilihat dari kemampuan peserta didik yang meningkat pada tahap question setelah tahap survey dilaksanakan.

\section{KESIMPULAN}

\section{A. Simpulan}

Berdasarkan hasil penelitian ini dapat disimpulkan beberapa hal sebagai berikut:

1. Dari proses perhitungan hasil pre-test dan post-test diperoleh thitung >ttabel.

2. Mengacu pada hasil pada kesimpulan nomor 1, penerapan strategi belajar Survey, Question, Read, Recite, Record, Review (SQ4R) telah berhasil meningkatkan hasil belajar peserta didik materi struktur atom kelas X SMA Muhammadiyah 1 Pekanbaru.

\section{B. Rekomendasi}

Rekomendasi yang dapat diberikan berdasarkan hasil, pembahasan, dan simpulan adalah sebagai berikut:

1. Menerapkan strategi belajar SQ4R sebagai pilihan strategi belajar agar mencapai hasil pembelajaran yang meningkat pada pesertadidik.

2. Jika peneliti lain ingin mengembangkan penelitian ini, hendaknya strategi ini dilakukan pada materi lainnya. Ini bertujuan agar dapat memperkuat pengaruh penggunaan strategi SQ4R dalam proses belajar mengajar dalam upaya peningkatan hasil belajar peserta didik di sekolah. 


\section{DAFTAR PUSTAKA}

Irianto, A. 2003. Statistika Konsep Dasar dan Aplikasi. Kencana. Jakarta

Gunawan, A. 2016. Penerapan Strategi SQ4R ntuk Meningkatkan Aktivitas dan Hasil

Belajar Larutan Penyangga Bagi Peserta Didik Kelas XI IPA 1 SMAN I Cepiring 2015/2016. Majalah Ilmiah Inspiratif, Vol.2 No.2 Janauari 201.6

Shoimin, A. 2014. 68 Model Pembelajaran Inovatif Dalam Kurikulum 2013. Ar Ruzz Media. Yogyakarta

Dimyati, Mudjiono. 2002. Belajar dan Pembelajaran. Rineka Cipta. Jakarta

Hayadi. 2007. Retorika Membaca Metode Model Teknik. Semarang. Rumah Indonesia. Mohammad Nazir. 2003. Metode Penelitian. Ghalia Indonesia. Jakarta

Nobunaga. 2008. Istilah Ilmu Kimia. Gramedia Pustaka Utama. Jakarta Riduwan

Sunarto. 2010. Pengantar statistika. Alfabeta. Bandung

Slameto. 2003. Belajar dan Faktor yang Mempengaruhinya. Rineka Cipta. Jakarta

Usmansyah, W., Herdini, Copriady, C. 2019. Penerapan strategi belajar SQ4R untuk meningkatkan hasil belajar peserta didik. Jurnal Pendidikan Kimia Universitas Riau, 4(2): 47 - 56 